\title{
Chromatin integrity of ram spermatozoa. Relationships to annual fluctuations of scrotal surface temperature and temperature-humidity index
}

\author{
Malama, E ; Bollwein, H ; Taitzoglou, I A ; Theodosiou, T ; Boscos, C M ; Kiossis, E
}

\begin{abstract}
The objective of the present study was to explore the potential relationships of ovine sperm chromatin integrity, quantified using the sperm chromatin structure assay (SCSA), to the heat load of the scrotum and the discomfort felt by the animals because of fluctuations of microclimatic factors at different time periods before ejaculation. Ejaculates were collected once per week from five Chios rams and four East Friesian rams for 12 months and stored in liquid nitrogen. Frozen-thawed semen samples were analyzed using the SCSA, to determine the DNA fragmentation index (DFI) and the percentage of cells outside the main sperm population $(\% \mathrm{DFI})$ in each one of the samples. Scrotal surface temperature (SST) of each ram was measured using an infrared thermometer on a daily basis. Ambient air temperature and relative humidity were recorded at hourly intervals throughout the experimental period and temperaturehumidity index (THI) was used to assess the discomfort felt by the rams. Mean values of SST (SST mean) and THI (THI mean) were computed for eight different time periods (up to 61 days) preceding each ejaculation day (Day 0). A linear mixed-effect model analysis was performed to describe the relation of SCSA parameters to collection month, SST mean, and THI mean of different time periods before ejaculation. The results of the statistical analysis revealed a relation of \%DFI to the SST mean of the last 12 days preceding ejaculation, namely the period that resembled the phase of epididymal maturation. On the contrary, the variation of DFI was most adequately described by the linear mixed-effect model applied for Days 54 to 48 before ejaculation, which resembled the phase of spermatogonial mitoses. The effect of collection month was significant for DFI and \%DFI, with semen samples collected in September and February exhibiting the lowest DFI values; a less profound seasonal pattern was detected for \%DFI. The effect of THI mean on DFI and \%DFI was proven nonsignificant in regard to all time periods. In conclusion, a relation of SCSA parameters to SST mean of different periods before ejaculation was shown in the present study, implying an effect of scrotal microenvironment on intratesticular and epididymal sperm population. In contrast, we failed to detect any effect of microclimate-induced discomfort felt by the animals on the chromatin integrity of frozen-thawed ram spermatozoa.
\end{abstract}

DOI: https://doi.org/10.1016/j.theriogenology.2013.05.019

Posted at the Zurich Open Repository and Archive, University of Zurich

ZORA URL: https://doi.org/10.5167/uzh-88844

Journal Article

Accepted Version

Originally published at:

Malama, E; Bollwein, H; Taitzoglou, I A; Theodosiou, T; Boscos, C M; Kiossis, E (2013). Chromatin integrity of ram spermatozoa. Relationships to annual fluctuations of scrotal surface temperature and temperature-humidity index. Theriogenology, 80(5):533-541. 
DOI: https://doi.org/10.1016/j.theriogenology.2013.05.019 
1 Chromatin integrity of ram spermatozoa. Relationships to annual fluctuations of

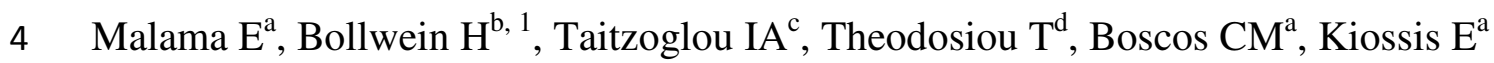

5

$6{ }^{a}$ Clinic of Farm Animals, School of Veterinary Medicine, Aristotle University of

7 Thessaloniki, St. Voutyra 11, 54627 Thessaloniki, Greece

$8{ }^{\mathrm{b}}$ Clinic for Cattle, University of Veterinary Medicine Hannover, Bischofsholer

9 Damm 15, D-30173 Hannover, 5 Germany

$10{ }^{\mathrm{c}}$ Laboratory of Physiology, School of Veterinary Medicine, Aristotle University of

11 Thessaloniki, University Campus, 54124 Thessaloniki, Greece

d Department of Informatics, Aristotle University of Thessaloniki, University

13 Campus, 54124 Thessaloniki, Greece

1 Present address: Clinic for Reproductive Medicine, Vetsuisse Faculty of the

21 University of Zurich, Winterthurerstr. 260, 8057 Zurich, Switzerland 
Abstract

The objective of the present study was to explore the potential relationships of ovine sperm chromatin integrity, as quantified by the Sperm Chromatin Structure Assay $\left(\mathrm{SCSA}^{\mathrm{TM}}\right)$, to the heat load of the scrotum and the discomfort felt by the animals due to fluctuations of microclimatic factors at different time periods prior to ejaculation. Ejaculates were collected once per week from five Chios rams and four East Friesian rams for 12 months and stored in liquid nitrogen. Frozen-thawed semen samples were analyzed using the $\mathrm{SCSA}^{\mathrm{TM}}$, in order to determine the DNA fragmentation index (DFI) and the percentage of cells outside the main sperm population (\%DFI) in each one of the samples. Scrotal surface temperature (SST) of each ram was measured by means of an infrared thermometer in daily basis. Ambient air temperature and relative humidity were recorded at hourly intervals throughout the experimental period and temperature-humidity index (THI) was used to assess the discomfort felt by the rams. Mean values of SST ( $\left.\mathrm{SST}_{\text {mean }}\right)$ and THI (THI mean $)$ were computed for eight different time periods (up to $61 \mathrm{~d}$ ) preceding each ejaculation day (0 d). Linear mixed-effect model (MLM) analysis was performed to describe the relation of SCSA parameters to collection month, $\mathrm{SST}_{\text {mean }}$ and $\mathrm{THI}_{\text {mean }}$ of different time periods prior to ejaculation. The results of the statistical analysis revealed a relation of $\% \mathrm{DFI}$ to the $\mathrm{SST}_{\text {mean }}$ of the last 12 days preceding ejaculation, namely the period that resembled the phase of epididymal maturation. On the contrary, the variation of DFI was most adequately described by the MLM applied for days 54 to 48 prior to ejaculation, which resembled the phase of spermatogonial mitoses. The effect of collection month was found significant for both DFI and \%DFI, with semen samples collected in September and February exhibiting the lowest DFI values; a less 
profound seasonal pattern was detected for \%DFI. The effect of $\mathrm{THI}_{\text {mean }}$ on DFI and

$49 \%$ DFI was proven non-significant in regard to all time periods. In conclusion, a 50 relation of SCSA parameters to $\mathrm{SST}_{\text {mean }}$ of different periods prior to ejaculation was 51 shown in the present study, implying an effect of scrotal microenvironment on both 52 intratesticular and epididymal sperm population. On the other hand, we failed to 53 detect any effect of microclimate-induced discomfort felt by the animals on the 54 chromatin integrity of frozen-thawed ram spermatozoa.

55

56 Key words: ram, sperm chromatin, SCSA, scrotal temperature, temperature-humidity 57 index 


\section{(n)}

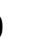

The susceptibility of sperm DNA to elevated testicular temperature and/or impaired local thermoregulation has been well documented in laboratory and farm animals [1]. In the ram, published data have demonstrated an adverse effect of experimental heat stress on sperm motility [2, 3], morphology [2, 4-7] and fertilizing capacity $[4,6,8]$; however little is known about the effect of increased temperature on the chromatin integrity of the ovine sperm [9]. Although recent experiments question its relation to the fertility potential of ovine sperm [10], assessment of sperm DNA stability using Sperm Chromatin Structure Assay $\left(\mathrm{SCSA}^{\mathrm{TM}}\right)$ provides useful information on ovine semen quality, that is not acquired by conventional semen tests [11].

The problem in studying the effect of elevated ambient temperature on spermatogenesis lies on the complex direct and indirect mechanisms through which temperature affects the physiological function of testicular and epididymal cells. Apart from the profound direct effect of heat or cold exposure on the male germ cells and their supporting tissues, fluctuations of microclimatic factors, and especially air temperature, may affect spermatogenesis through systematic physiological pathways. In the case of seasonal breeders (like rams), the role of ambient air temperature as modulating factor of seasonality should also be taken into account $[12,13]$.

The recording of intratesticular temperature for repeated-measurements experimental design, aiming to describe the lag effect of microclimatic fluctuations on spermatogenesis, is not compatible with animal welfare and endangers the reliability of the scientific results. In the ram, scrotal surface temperature (SST) is primarily regulated by the scrotum [14]. However, its close relation to the temperature of the 
underlying tissues, as demonstrated by Coulter et al. [15], enables the use of SST as an indicator of the heat load of the scrotum and underlying testes.

Apart from their effect on the scrotal microenvironment, microclimatic fluctuations are felt as discomfort of varying degree by the animal. The calculation of temperature-humidity index (THI), a formula that combines the temperature and relative humidity of the air, has been widely used to assess the effects of heat exposure on the productive performance of dairy cattle [16]. Finocchiaro et al. [17] have recently studied the relation between heat tolerance and milk production of Mediterranean sheep, using a THI to quantify environmental heat stress.

In the present study, the hypothesis that SST and microclimatic conditions have a lag effect on the chromatin integrity of ovine frozen-thawed spermatozoa was tested. Thus, the potential relations of SCSA parameters to SST and THI of eight different time periods (up to $61 \mathrm{~d}$ ) prior to ejaculation $(0 \mathrm{~d})$ were detected. Moreover, an attempt to investigate the effect of the month of semen collection and reveal any seasonal variations of SCSA parameters was also made.

\section{Materials and Methods}

\subsection{Animals}

Nine rams (five rams of Chios breed and four rams of East Friesian breed) were used as sperm donors in this study. At the beginning of the experiment, all rams were 36 to 48 months old; except for two East Friesian rams, that were 24 months old, and one Chios ram, that was 72 months old. Animals were housed under uniform conditions in the Institute of Reproduction and Artificial Insemination of 
Thessaloniki, Greece, and exposed to natural photoperiodic pattern and microclimatic conditions of the region $\left(40^{\circ} 41^{\prime} 00.70^{\prime \prime} \mathrm{N}, 22^{\circ} 51^{\prime} 53.47^{\prime \prime} \mathrm{E}\right)$. All rams had been previously acclimatized to local microclimate for at least two years. The feeding of the rams was uniform and included alfalfa hay and a commercial concentrate for sperm donor rams. No hormonal or other treatment affecting the physiological reproductive performance of the rams was administered during the experimental period. Animal housing and handling were in compliance with the European Commission Recommendation 2007/526/EC on the guidelines for the accommodation and care of animals used for experimental and other scientific purposes.

\subsection{Semen collection and processing}

Semen was collected in weekly routine from May $9^{\text {th }}, 2007$ until April $30^{\text {th }}$, 2008. The same two persons handled the rams and collected the ejaculates throughout the experimental period. Semen was collected between 08.30 and 09.00 a.m. on the ejaculations days. Rams mounted a ewe after several minutes of sexual preparation (false mounts) and one ejaculate was collected in Hannover type artificial vagina. Sperm concentration of each ejaculate was determined in 1:20 v:v diluted semen samples (with $0.9 \%$ normal saline) using a photometer (Dr Lange Photometer LP1, Minitüb, Germany). The percentage of motile spermatozoa (motility, \%) was microscopically assessed. An eosin-nigrosin staining was performed to determine the percentage of live (eosin-negative) spermatozoa (viability, \%). Eosin-nigrosin stained aliquots were also used for the evaluation of sperm morphology, in order to determine the percentage of morphologically normal spermatozoa (normal spz, \%), as previously described by Barth and Oko [18]. Conventional semen traits (ejaculate volume, sperm 
concentration, motility, viability, morphology) were always evaluated by the same examiner within short time after ejaculation. Regardless of their quality, all the ejaculates were further processed for cryopreservation. Two fractions (with and without glycerol) of a TRIS-egg yolk-citrate extender (3.02\% wt/vol TRIS, 1.75 $\mathrm{wt} / \mathrm{vol}$ citric acid, $1.36 \mathrm{wt} / \mathrm{vol}$ fructose, $20 \% \mathrm{v}: \mathrm{v}$ egg yolk) were used for a two-step dilution based on the method of Kupferschmied et al. [19] modified for ram. At first step $\left(37^{\circ} \mathrm{C}\right)$, semen was diluted to $800 \times 10^{6}$ spermatozoa/mL concentration using the glycerol-free fraction and gradually cooled to $5^{\circ} \mathrm{C}$. At second step $\left(5^{\circ} \mathrm{C}\right)$, semen samples were diluted 1:1 v:v with the glycerolated fraction of the extender (12\% v:v glycerol was added) to a final concentration of $400 \times 10^{6}$ spermatozoa $/ \mathrm{mL}$. Diluted semen was packed in $0.25 \mathrm{~mL}$ straws (IMV, L' Aigle, France) and equilibrated for 2 hours at $5^{\circ} \mathrm{C}$. Filled straws were plunged into liquid nitrogen (LN) after a 5-minute freezing in $\mathrm{LN}$ vapors (at $10 \mathrm{~cm}$ above the surface of liquid nitrogen for $3 \mathrm{~min}$ and at $4 \mathrm{~cm}$ for $2 \mathrm{~min}$ ) of an open dewar (Statebourne-Cryogenics, UK). The storage period of semen ranged from 2 to 13 months.

2.3. Membrane integrity and acrosomal status after thawing

Membrane integrity and acrosomal status of the frozen-thawed semen samples were flow cytometrically evaluated using a double staining with propidium iodide (PI) and peanut agglutinin conjugated with fluorescein isothiocyanate (FITC-PNA), as previously described by Nagy et al. [20] after modification. For this purpose, an Epics XL-MCL flow cytometer (Beckman Coulter Inc., Fullerton, California, U.S.A.) was used. Three straws of each frozen semen sample were thawed $\left(37^{\circ} \mathrm{C}, 30 \mathrm{~s}\right)$, pooled and diluted to a final concentration of $5 \times 10^{6}$ spermatozoa/mL using Tyrode's medium 
158 (320 mO, pH 7.4). Two aliquots of each pooled sample were stained by adding $3 \mu \mathrm{L}$ 159 of PI working solution (2.99 mM; Propidium Iodide No P4170, Sigma-Aldrich

160 Chemie $\mathrm{GmbH}$, Germany) and $5 \mu \mathrm{L}$ of FITC-PNA working solution $(100 \mu \mathrm{g} / \mathrm{mL}$ 161 distilled water; FITC-PNA No L7381, Sigma-Aldrich Chemie GmbH, Germany) to $162500 \mu \mathrm{L}$ of diluted semen. Stained aliquots were incubated at $37^{\circ} \mathrm{C}$ in humidified 163 atmosphere with $5 \% \mathrm{CO}_{2}$ for 15 min before being analyzed in the flow cytometer 164 (Epics XL-MCL, Beckman Coulter Inc., Fullerton, California, U.S.A.). Detector 1 165 (515 to $545 \mathrm{~nm}$ ) and $3(>670 \mathrm{~nm}$ ) were set to detect FITC-PNA and PI fluorescence, 166 respectively, and 10000 events were counted per sample. The percentage of 167 membrane-intact (viable), acrosome-intact spermatozoa (\%VAI, \%) was determined 168 using EXPO 32 ADC XL4 Color software (Beckman Coulter Inc., Fullerton, 169 California, U.S.A).

\subsection{Sperm Chromatin Structure Assay}

Sperm Chromatin Structure Assay (SCSA ${ }^{\mathrm{TM}}$ ) was conducted by means of an Epics XL-MCL flow cytometer (Beckman Coulter Inc., Fullerton, California, U.S.A.).

175 Flow cytometric data were acquired using EXPO 32 ADC XL4 Color software 176 (Beckman Coulter Inc., Fullerton, California, U.S.A.). Flow rate was set to 200 177 events/s and 10000 events were counted per sample. Detectors 1 and 3 were used for 178 detection of green (515 to $530 \mathrm{~nm})$ and red fluorescence (>630 nm), respectively.

179 Three straws of each semen sample were thawed $\left(37^{\circ} \mathrm{C}, 30 \mathrm{~s}\right)$ and pooled. 180 Pooled samples were extended immediately after thawing to a final concentration of $1812 \times 10^{6}$ spermatozoa/mL using TNE buffer (0.01 M TRIS-HCl, $0.15 \mathrm{M} \mathrm{NaCl}, 1 \mathrm{mM}$ 182 EDTA, $\mathrm{pH}$ 7.4). For each sample, DNA fragmentation was evaluated using the 
183

SCSA $^{\mathrm{TM}}$ as previously described by Evenson and Jost [21]. Acid-induced denaturation of DNA in situ was achieved by adding $400 \mu \mathrm{L}$ of acid-detergent solution (0.1\% v:v Triton X-100, $0.15 \mathrm{M} \mathrm{NaCl}, 0.08 \mathrm{~N} \mathrm{HCl}, \mathrm{pH} 1.2)$ to $200 \mu \mathrm{L}$ of extended semen sample. After $30 \mathrm{~s}$, sperm was stained by adding $1.2 \mathrm{~mL}$ of acridine orange (AO) staining solution containing $6 \mu \mathrm{g}$ purified AO (Acridin Orange, ‘ $\ddot{Y}$, chromatographically purified No 04539, Polysciences Inc., U.S.A.) per mL of buffer (0.1 M citric acid, 0.2 M Na2HPO4, 1 mM EDTA, 0.15 M NaCl, pH 6.0). Stained sperm were incubated on ice for 3 min before flow cytometric analysis.

SCSA data were analyzed using XDAS 4.40 software [22]. The mean extent of sperm DNA fragmentation (DNA fragmentation index, DFI), calculated by the ratio $\mathrm{red} /(\mathrm{red}+$ green $)$ fluorescence multiplied by 1000, and the percentage of sperm outside the main population (\%DFI, \%) in each sample were determined as previously described by Evenson et al. [23].

\subsection{Choice of time periods preceding ejaculation day}

The potential relations of SCSA parameters to SST and THI encountered at eight different time periods prior to each ejaculation day $(0 \mathrm{~d})$ were investigated by analyzing the data set in a way similar to that previously described for the bull [24]. The time periods were set as follows: 1 to $12 \mathrm{~d}$ (period 1), 13 to $19 \mathrm{~d}$ (period 2), 20 to $26 \mathrm{~d}$ (period 3), 27 to $33 \mathrm{~d}$ (period 4), 34 to $40 \mathrm{~d}$ (period 5), 41 to $47 \mathrm{~d}$ (period 6), 48 to $54 \mathrm{~d}$ (period 7) and 55 to $61 \mathrm{~d}$ (period 8). Since spermatogenesis proceeds via an orderly series of events, it is possible to estimate the approximate stage of germ cell development at various intervals prior to the time sperm becomes available for ejaculation. Previous experiments have shown that epididymal passage in the ram has 
duration of 12 to 13 days [25]; thus, the duration of period 1 was set to 12 days to resemble the phase of epididymal maturation. Based on the description of the ovine seminiferous epithelium cycle by Cardoso and Gueiroz [26], periods 2 and 3 (with total 14-day duration) resembled the later and earlier steps of spermiogenesis, respectively, periods 4 and 5 with total 14-day duration resembled the phase of meiotic divisions and periods 6 to 8 resembled the phase of mitoses of spermatogonia.

\subsection{Assessment of SST}

SST was measured on a daily basis for six out of seven days each week. Daily SST $\left({ }^{\circ} \mathrm{C}\right)$ of each ram was assessed as the mean value of two different measurements, each one at the posterior scrotal surface over the midpoint of horizontal and vertical axis of each underlying testis. The surface temperature of a circular area of approximately 4-centimeter diameter was measured using a non-contact wide range infrared thermometer (42530, Extech Instruments Corporation, U.S.A.) from a distance of $25 \mathrm{~cm}$. Based on a previous report on the daily circadian pattern of SST [27], all measurements were performed between 11.00 and 12.00 a.m.; this time of the day coincided with the time following animal feeding, so that the rams were standing at least $30 \mathrm{~min}$ prior to measurement. Mean values of scrotal surface temperature $\left(\mathrm{SST}_{\text {mean }}\right)$ of each ram were calculated out of the respective daily values for the time periods described in section 2.5.

\subsection{Calculation of THI}



was assessed using the THI previously proposed by Kelly and Bond [28]. For the

calculation of THI, microclimatic factors [ambient air temperature $\left({ }^{\circ} \mathrm{C}\right)$, relative humidity (\%)] were recorded at hourly intervals (24 observations per day), using a digital data logger (HOBO 8, Onset, Massachusetts, U.S.A.) placed in the barn, in order to acquire values of daily maximum temperature and daily mean relative humidity (midnight and 23.59 p.m. were considered as the beginning and end of each day, respectively). As previously suggested by Finocchiaro et al. [17], mean THI $\left(\mathrm{THI}_{\text {mean }}\right)$ values were calculated by the following formula for each time period described in section 2.5:

$$
\left(T H I_{\text {mean }}\right)_{i}=\left(T_{\text {max }}\right)_{i}-0.55 \times\left[\left(1-\left(R H_{\text {mean }}\right)_{i} / 100\right] \times\left[\left(T_{\text {max }}\right)_{i}-14.4\right]\right.
$$

where $\mathrm{THI}_{\text {mean }}$ represents the calculated $\mathrm{THI}$ of period $\mathrm{i}, \mathrm{T}_{\max }\left({ }^{\circ} \mathrm{C}\right)$ the mean value of daily maximum temperatures of period $\mathrm{i}\left(\mathrm{i}=1\right.$ to 8 ), $\mathrm{RH}_{\text {mean }}$ the mean value of relative humidity of period i.

\subsection{Statistical analysis}

The relations between dependent variables (DFI, \%DFI) and the set of independent variables (breed, age class, month of semen collection, $\mathrm{SST}_{\text {mean }}, \mathrm{THI}_{\text {mean }}$ ) were assumed to be linear and assessed by linear mixed-effects model (MLM) analysis using the NLME [29] and MULTCOMP [30] packages of the R version 2.13.0 (13.4.2011) statistical programming language [31]. Data of five ejaculation days (in $3^{\text {rd }}, 22^{\text {nd }}, 34^{\text {th }}, 40^{\text {th }}$ and $44^{\text {th }}$ experimental week) were not included in statistical analysis; the reason was missing values due to technical issues (straws damaged during cryopreservation and/or transport) or missing ejaculates (ejaculates 
of several rams were used for the AI needs of the Institute). Thus, statistical analysis was applied for 43 ejaculates per ram $(\mathrm{N}=387)$. To assess the effect of age, the rams were classified into three age classes (2, 3 to 4 and 6 years old). The dependent variables were modeled as function of the effects of independent variables:

$$
Y_{j k}=\mu+\operatorname{ram}_{j} / \text { week }_{k}+b_{1}\left(\text { breed }_{l}\right)+b_{2}\left(\text { age }_{m}\right)+b_{3}\left(\text { month }_{n}\right)+b_{4}\left[\left(S S T_{\text {mean }}\right)_{j i k}\right]+
$$

$$
b_{5}\left[\left(T H I_{\text {mean }}\right)_{i k}\right]+\mu
$$

where Y represents the individual observation of DFI or \%DFI of the semen sample collected from ram $\mathrm{j}$ ( $\mathrm{j}=1$ to 9 ) in week $\mathrm{k}(\mathrm{k}=1$ to 43$), \mu$ the overall mean of the population, ram the random effect of ram $\mathrm{j}$ repeated in week $\mathrm{k}$, breed the fixed effect of breed $1(l=1,2)$ of ram $j$, age the fixed effect of age class $m(m=1$ to 3$)$ of ram $j$, month the fixed effect of month of semen collection $n(n=1$ to 12$), \mathrm{SST}_{\text {mean }}$ the fixed effect of $\mathrm{SST}_{\text {mean }}$ of ram $\mathrm{j}$, in period $\mathrm{i}(\mathrm{i}=1$ to 8 ) preceding the ejaculation of week $\mathrm{k}$, $\mathrm{THI}_{\text {mean }}$ the fixed effect of $\mathrm{THI}_{\text {mean }}$ of period $\mathrm{i}$ ( $\mathrm{i}=1$ to 8 ) preceding the ejaculation of week $\mathrm{k}, \mathrm{b}_{1-5}$ the estimated regression coefficients of the fixed effects and $\mu$ the random error of the MLM.

Independent variables of the formula (breed, age, month, $\mathrm{SST}_{\text {mean }}$ and $\mathrm{THI}_{\text {mean }}$ ) were added in a stepwise fashion to a basic model including only the random effect of ram. Thus, eight different groups of MLMs were created for each SCSA parameter, one for each time period prior to ejaculation. The simplest MLM in each group was the basic model, while the most complicated was the model which included the effects of ram, breed, age, month, $\mathrm{SST}_{\text {mean }}$ and $\mathrm{THI}_{\text {mean }}$ of the respective time period. To reach the best-fitting model of each group, the basic and subsequent MLMs were compared in terms of goodness-of-fit performing ANOVA at a 0.05 significance level. The -2 log-likelihood was used as a measure of the goodness-of-fit of each MLM. Fixed effects that did not improve the goodness-of-fit of the MLM were not 
included in the final model applied for each period. To determine the time period, the MLM of which most adequately described the relation between the dependent and independent variables, the best-fitting MLMs of the eight groups were compared in pair-wise manner as described above.

Relations among semen traits, as well as daily SST, THI and microclimatic factors, were determined by calculating Spearman's correlation coefficient $\left(\mathrm{r}_{\mathrm{s}}\right)$.

\section{Results}

Descriptive statistics of the microclimatic factors and THI observed throughout the experimental period are presented in Table 1 . About $1 / 5$ of the hourly observations of air temperature and relative humidity exceeded $25{ }^{\circ} \mathrm{C}$ and $75 \%$, respectively (Figure 1). Rams of the experimental group spent a 6-week period in midsummer under conditions of elevated temperature (daily mean temperature $>25{ }^{\circ} \mathrm{C}$; Figure 1). Rams experienced very low temperatures (daily mean temperature $<5{ }^{\circ} \mathrm{C}$ ) for 22 days during winter months, with most of them being observed in late December and early January (Figure 1).

Scrotal surface temperature ranged from 12.80 to $38.90{ }^{\circ} \mathrm{C}$ (mean across the nine rams $\pm \mathrm{SD}, 29.43 \pm 3.56{ }^{\circ} \mathrm{C}$; Table 1$)$. The variation of daily SST followed a distinct seasonal pattern for rams of both breeds (Figure 2). Its mean values across the nine rams were strongly related to daily mean temperature $\left(r_{s}=0.946, P<0.001\right.$, onetailed test $)$ and daily THI $\left(\mathrm{r}_{\mathrm{s}}=0.891, \mathrm{P}<0.001\right.$, one-tailed test $)$, while a weaker negative relation was detected between SST and daily mean relative humidity $\left(r_{s}=-0.448\right.$, $\mathrm{P}<0.001$, one-tailed test). 
Table 1 = "Tables.docx"

Figure 1 = "Fig1.tif"

Figure 2 = "Fig2.tif"

The mean values (across all rams) $\pm \mathrm{SD}$ and the range of conventional semen traits and flow cytometrically analyzed sperm characteristics throughout the collection period are presented in Table 1. More than half of the ejaculates had motility and viability $>70 \%$ (60\% and $68 \%$ of the ejaculates, respectively). In the contrary, the mean percentage of viable spermatozoa (\%VAI) in frozen-thawed semen samples did not exceed the acceptable threshold of $50 \%$ (mean \pm SD, $10.50 \% \pm 8.21 \%$; Table 1 ).

A positive correlation was found between the two SCSA parameters $\left(r_{s}=0.623\right.$, $\mathrm{P}<0.01$, two-tailed test). DFI and \%DFI were negatively related to the percentage of live $\left(r_{\mathrm{s}}=-0.396, \mathrm{P}<0.01\right.$, two-tailed test and $\mathrm{r}_{\mathrm{s}}=-0.489, \mathrm{P}<0.01$, two-tailed test, respectively) and morphologically normal spermatozoa $\left(\mathrm{r}_{\mathrm{s}}=-0.264, \mathrm{P}<0.01\right.$, two-tailed test and $\mathrm{r}_{\mathrm{s}}=-0.241, \mathrm{P}<0.01$, two-tailed test, respectively), while none of them showed a significant relation to \% VAI ( $\mathrm{P}>0.05$ for both SCSA parameters).

Based on the goodness-of-fit criteria, the relation of \%DFI was best described by the MLM applied for time period 1 (Table 2). On the contrary, MLM of time period 7 was found to be the most adequate to describe the relation of DFI to the set of independent variables (Table 2).

Table 2 = "Tables.docx"

The estimated regression coefficients of the fixed effects of the best-fitting MLMs applied for each SCSA parameter are presented in Table 3. DFI and \%DFI 
were negatively related to $\mathrm{SST}_{\text {mean }}$ of the periods with the best-fitting MLMs (Table $3)$.

As shown in Table 3, the effect of breed was proven significant for all dependent variables, with rams of East Friesian breed exhibiting slightly higher values of SCSA parameters compared with Chios rams. On the other hand, $\mathrm{THI}_{\text {mean }}$ did not improve the goodness-of-fit of the applied MLMs in regard to either DFI or \%DFI. Month explained a significant part of variation of DFI and \%DFI (Table 3). Pair-wise comparisons between months revealed a significant decrease of DFI in February and September, while \%DFI values showed a significant deviation from the observed annual pattern only for semen samples collected during August (Figure 3).

Table 3 = "Tables.docx"

Figure 3 = "Fig3.tif"

\section{Discussion}

In our study, SCSA parameters were determined in frozen-thawed ram semen samples. Although the detrimental effect of cryopreservation on membrane integrity was profound (mean $\% \mathrm{VAI} \pm \mathrm{SD}, 10.50 \% \pm 8.21 \%$ ), the mean post-thaw values of SCSA parameters compared favorably to those reported previously [11, 32]. The postthaw deterioration of membrane integrity could not be easily explained. This finding could be attributed either to the stress suffered by the frozen-thawed spermatozoa during the dilution step of the PI/FITC-PNA staining protocol or to the freezing protocol applied in the present study. However, the levels of SCSA parameters did not suggest an analogous impact of cryopreservation on sperm chromatin stability. The 
divergent effects of cryopreservation on spermatozoal DNA and membrane integrity were reflected by the non-significant correlations found between SCSA parameters and \%VAI. This finding was in agreement with results of previous studies demonstrating a non-significant or low correlation between sperm chromatin integrity and viability of frozen-thawed ovine semen $[11,33]$.

According to our results, SST was proven a significant predictor of sperm DNA fragmentation. Mean SST values were comparable with those of previous reports, where rams were kept under experimental thermoneutral conditions [14, 15, 34]. In our study, SST was recorded under a wide range of natural microclimatic conditions and showed a close response to the fluctuations of air temperature and THI; the response of SST to changes of ambient temperature has been previously reported by Kastelic et al. [34]. It is known that independent thermoregulatory [27, 35] and local blood flow controlling mechanisms [36] are responsible for maintaining the balance of scrotal heat loss and gain. Dutt et al. [36] have shown that the initial blood flow increase is followed by a remarkable reduction after 5 to 7 days of constant thermal stimulus, implying an adaptation of scrotal thermoregulation to environmental conditions. Given that the rams of the present experiment were exposed to natural microclimate with extended periods (more than 15 days) of cold (daily mean air temperature $<5{ }^{\circ} \mathrm{C}$ ) and heat (daily mean air temperature $>25{ }^{\circ} \mathrm{C}$ ) exposure, a longterm acclimatization and adaptation of scrotal thermoregulatory and circulatory mechanisms towards the protection of underlying tissues against extreme temperatures can be assumed.

Regarding the lag effect of SST on chromatin integrity, we detected a significant relation of DFI to $\mathrm{SST}_{\text {mean }}$ of time period 7. This finding implies an effect of scrotal microenvironment on testicular sperm cells undergoing mitotic divisions, 
which is manifested 48 to 54 days later as altered susceptibility of ejaculated spermatozoa to acid-induced DNA denaturation. Previous studies in the ram have shown that the effects of interference with scrotal thermoregulation on motility [3], morphology and viability $[4,37]$ of ejaculated spermatozoa are evident up to 50-60 days after the end of heat treatment. Ibrahim et al. [37] described a two-phase peak of pyriform-headed spermatozoa ejaculated on the $33^{\text {rd }}$ and $57^{\text {th }}$ day following scrotal insulation with a 9-day interval between them. In the latter study, an increase of spermatozoa accumulating clusterin, a glucoprotein produced by Sertoli and epididymal epithelial cells in response to heat and oxidative stress, was demonstrated up to the $57^{\text {th }}$ day post-insulation; based on that finding the authors suggested a testicular origin of the capacity of ejaculated spermatozoa for accumulating clusterin on their surface [37]. The results of our study imply that the amount of DNA fragmentation of frozen-thawed ovine spermatozoa can be partly attributed to the scrotal microenvironment encountered by them at very early phases of their intratesticular development.

In contrast to DFI, the percentage of DNA-damaged spermatozoa (\%DFI) in the ejaculate was related to the scrotal temperatures recorded the last 12 days prior to ejaculation. Values of \%DFI were negatively related to SST values of period 1, which resembled the phase of epididymal maturation of ram spermatozoa. It is known that spermatozoal chromatin stabilization is completed during epididymal maturation by the formation of disulphide bonds within and between protamine molecules $[38,39]$, while the epididymis is also responsible for the secretion of a complex array of antioxidant factors, offering protection to epididymal spermatozoa against ROSinduced DNA damage [40]. Though not providing clear evidence on a causative relation, recent studies in the ram have shown a positive correlation of SCSA 
parameters and lipid peroxidation levels in seminal plasma [41] and spermatozoa [41, 42]. Although a gradual resistance to chromatin decondensation is observed during epididymal transit $[32,43]$, ram spermatozoa of the caput and corpus epididymis still suffer from a considerable degree of chromatin instability [32]. Results of our study suggest that scrotal microenvironment can interfere with the process of sperm chromatin stabilization in the epididymis; however further experimental data are necessary to support such an assumption.

The estimated regression coefficients describing the relation of DFI and \%DFI to $\mathrm{SST}_{\text {mean }}$ of period 7 and 1, respectively, were found negative. We expected that fluctuations of scrotal surface temperature would adversely interfere with normal testicular and epididymal function, resulting in a positive relation between SCSA parameters and $\mathrm{SST}_{\text {mean }}$; however, that was not the case. Though collected after summer (when a distinct increase of SST values was observed), semen samples of September and October exhibited lower DFI and \%DFI values.

Apart from $\mathrm{SST}_{\text {mean }}$, month was found to explain a significant part of the total variation of the two SCSA parameters, which implies that sperm chromatin integrity is subject to the combined effect of both scrotal temperature and season. Given this finding and the knowledge that ram is a short-day breeder exhibiting the peak of its reproductive performance in late summer and autumn [13], we attributed the negative relation between SCSA parameters and $\mathrm{SST}_{\text {mean }}$ to a potential compensative effect of reproductive seasonality on DNA damage processes caused by elevated SST. A similar observation has been previously made by Ibrahim [44], who showed that the elevation of ambient air temperature during summer did not decrease the sexual activity and semen quality of crossbred Chios rams kept under subtropical-arid climatic conditions. 

distinct seasonal pattern for rams of both breeds, with semen samples collected in February and from August to October exhibiting decreased levels of DFI. Though not as pronounced as in the ewe, seasonal fluctuations of sexual activity are also evident in the ram [13]. Published data indicate late summer and autumn as the seasons of higher reproductive performance of Chios [45, 46] and East Friesian sheep [46, 47]. The wave-like seasonal pattern of DFI variation described in our study is not in agreement with a recent work of Garcia-Macias et al. [9], who demonstrated an increase of ram spermatozoal chromatin decondensation in July and August and the lack of any significant differences between the SCSA parameters of semen samples collected in the breeding and non-breeding season. Similar results were also published by Rodriguez et al. [43], who reported a slightly higher percentage of ovine spermatozoa with stable nuclei in the non-breeding season, but detected no significant differences in comparison with the breeding season. The fluctuating pattern of \%DFI observed in our study was not as clear as that of DFI and the rams of the two breeds exhibited slight differences in the monthly variation of \%DFI. This was attributed to the individual factor of a single East Friesian ram that affected the mean \%DFI values of the breed (data not shown), rather than to a breed-related feature.

The hypothesis, that DNA integrity of ejaculated spermatozoa was related to the degree of discomfort felt by the animals due to microclimatic fluctuations at different time periods prior to ejaculation, was also tested in the present study. The values of $\mathrm{THI}_{\text {mean }}$ inserted in statistical analysis reflected periods of varying environmental burden, including phases of thermoneutral conditions, heat or cold exposure. Our results showed that $\mathrm{THI}_{\text {mean }}$ did not improve the goodness of fit of the statistical models applied for any SCSA parameter. This could be partly attributed to the high correlation 
coefficient describing the relation of $\mathrm{SST}_{\text {mean }}$ and $\mathrm{THI}_{\text {mean }}$ (data not shown); in this case, the addition of the predicting variable $\mathrm{THI}_{\text {mean }}$ would not offer any additional clue on the explanation of the variance of SCSA parameters. The comparison of MLMs that included either $\mathrm{SST}_{\text {mean }}$ or $\mathrm{THI}_{\text {mean }}$, when all other statistical parameters were kept constant, revealed that the former were more adequate to describe the variance of SCSA parameters, while the latter showed a non-significant effect of $\mathrm{THI}_{\text {mean }}$ to DFI and \%DFI (data not shown). Our results are in agreement with these of Moule and Waites [48], who showed that cooling of the scrotum had a beneficial effect on semen quality of Merino rams exposed to whole-body short-term heat stress and suggested that the efficiency of the heat-dissipating properties of the scrotum alone decided the magnitude of the adverse effects of short-term elevation of environmental temperature on semen quality.

In conclusion, our results implied an effect of SST on sperm at very early stages of spermatogenesis and epididymal maturation, but no influence of microclimaterelated discomfort as quantified by THI. Given the kind of relation between SCSA parameters and $\mathrm{SST}_{\text {mean }}$, we assume that seasonality of ram reproductive performance can compensate for the potential effect of elevated summer temperatures on DNA stability. However, a larger-scale experimental investigation of such an assumption is necessary, in order to clarify the combined influence of season and microclimate on DNA quality of ram spermatozoa.

\section{Acknowledgments}

The authors wish to acknowledge the assistance of Dr. Dimitrios Vafeiadis, Arseniadi Athanasia and Ioannis Panagiotidis, veterinarians at the Institute of 
Reproduction and Artificial Insemination of Thessaloniki, Greece, as well as the valuable help of the animal handlers and laboratory staff of the Institute. The authors are also indebted to Christel Hettel and Karin Loeppen, technical assistants in the Sperm Laboratory, Clinic for Cattle, University of Veterinary Medicine Hannover, Germany for their unreserved and friendly support. Special thanks are also given to Dr. Apostolos Sioutas, meteorologist in the Hellenic National Meteorological Service, for his scientific advice.

\section{References}

[1] Setchell, BP. The effects of heat on the testes of mammals. Anim Reprod 2006; 3(2): 81-91.

[2] Moreira EP, Moura ADA, de Araujo AA. Effects of scrotal insulation on testis size and semen criteria in Santa Ines hairy sheep raised in the state of Ceara, northeast of Brazil. Revista Brasileira De Zootecnia-Braz J Anim Sci 2001; 30(6): 1704-11.

[3] Arman C, Casares PIQ, Sanchez-Partida LG, Setchell BP. Ram sperm motility after intermittent scrotal insulation evaluated by manual and computer-assisted methods. Asian J Androl 2006; 8(4): 411-8.

[4] Braden AWH, Mattner PE. Effects of scrotal heating in ram on semen characteristics, fecundity, and embryonic mortality. Aust J Agric Res 1970; 21(3): 509-18.

[5] Rathore AK. Acrosomal abnormality in ram spermatozoa due to heat stress. Br Vet J 1970; 126(8): 440-3. 
[6] Rathore AK. Fertility of rams heated for 1, 2, 3, and 4 days, mated to superovulated ewes. Aust J Agric Res 1970; 21(2): 355-8.

[7] Rathore AK. Morphological changes in ram spermatozoa due to hot-room exposure for varying periods. Br Vet J 1970; 126(6): 277-81.

[8] Mieusset R, Casares PQ, Partida LGS, Sowerbutts SF, Zupp JL, Setchell BP. Effects of heating the testes and epididymides of rams by scrotal insulation on fertility and embryonic mortality in ewes inseminated with frozen-semen. J Reprod Fertil 1992; 94(2): 337-43.

[9] Garcia-Macias V, Martinez-Pastor F, Alvarez M, Borragan S, Chamorro CA, Soler AJ et al. Seasonal changes in sperm chromatin condensation in ram (Ovis aries), red deer (Cervus elaphus), and brown bear (Ursus arctos). Journal of Andrology 2006; 27(6): 837-46.

[10] Nordstoga AB, Krogenæs A, Nødtvedt A, Farstad W, Waterhouse K. The relationship between post-thaw sperm DNA integrity and non-return rate among Norwegian cross-bred rams. Reprod Domest Anim 2012 Aug 9; doi: 10.1111/j.1439-0531.2012.02132.x.

[11] Peris SI, Morrier A, Dufour M, Bailey JL. Cryopreservation of ram semen facilitates sperm DNA damage: Relationship between sperm andrological parameters and the Sperm Chromatin Structure Assay. J Androl 2004; 25(2): 224-33.

[12] Gündo• an M, Baki D, Yeni D. Reproductive seasonality in sheep. Acta Agriculturae Scandinavica, Section A - Anim Sci 2003; 53(4): 175-9.

[13] Rosa HJD, Bryant MJ. Seasonality of reproduction in sheep. Small Rumin Res 2003; 48(3): 155-71. 
[14] Kastelic JP, Cook RB, Coulter GH. Contribution of the scrotum and testes to scrotal and testicular thermoregulation in bulls and rams. J Reprod Fertil 1996; 108(1): 81-5.

[15] Coulter GH, Senger PL, Bailey DR. Relationship of scrotal surface temperature measured by infrared thermography to subcutaneous and deep testicular temperature in the ram. J Reprod Fertil 1988; 84(2): 417-23.

[16] West JW. Effects of heat-stress on production in dairy cattle. J Dairy Sci 2003; 86(6): 2131-44.

[17] Finocchiaro R, van Kaam JBCHM, Portolano B, Misztal I. Effect of heat stress on production of Mediterranean dairy sheep. J Dairy Sci 2005; 88(5): 1855-64.

[18] Barth A, Oko R. Abnormal morphology of bovine spermatozoa. $1^{\text {st }}$ ed. Ames Iowa: Iowa State University Press; 1989.

[19] Kupferschmied HF, Muther E. Experience with artificial insemination and estrus synchronization in goats. Schweizer Archiv für Tierheilkunde 1977; 119(10): 405-13. German.

[20] Nagy S, Jansen J, Topper EK, Gadella BM. A triple-stain flow cytometric method to assess plasma- and acrosome-membrane integrity of cryopreserved bovine sperm immediately after thawing in presence of egg-yolk particles. Biol Reprod 2003; 68(5): 1828-35.

[21] Evenson D, Jost L. Sperm Chromatin Structure Assay is useful for fertility assessment. Methods Cell Sci 2000; 22(2): 169-89.

[22] Beisker W. A new combined integral-light and slit-scan data analysis system (DAS) for flow cytometry. Comput Methods Programs Biomed 1994; 42(1): $15-26$. 
[23] Evenson DP, Jost LK, Baer RK, Turner TW, Schrader SM. Individuality of DNA denaturation patterns in human sperm as measured by the Sperm Chromatin Structure Assay. Reprod Toxicol 1991; 5(2): 115-25.

[24] Malama E, Kiossis E, Theodosiou T, Boscos C, Bollwein H. Lag effect of microclimatic conditions on DNA integrity of frozen-thawed bovine sperm. Anim Reprod Sci 2012; 136(1-2): 33-41.

[25] Amir D, Ortavant R, Bure A. Influence de la fréquence des collectes sur la durée du transit des spermatozoïdes dans le canal épididymaire du bélier. Ann Biol Anim Bioch Biophys 1968; 8(2): 195-207. French.

[26] Cardoso FM, Queiroz GF. Duration of the cycle of the seminiferous epithelium and daily sperm production of Brazilian hairy rams. Anim Reprod Sci 1988; 17(1-2): 77-84.

[27] Maloney SK, Mitchell D. Regulation of ram scrotal temperature during heat exposure, cold exposure, fever and exercise. J Physiol 1996; 496(2): 421-30.

[28] Kelly CF, Bond TE. Bioclimatic factors and their measurement. In: National Academy of Science, editors. A guide to environmental research on animals, Washington D.C. USA: Printing and Publishing Office, National Academy of Science; 1971, p. 7-92.

[29] Pinheiro J, Bates D, DebRoy S, Sarkar D, The R Development Core Team. NLME: Linear and nonlinear mixed effects models. R package version 3.1-100 [Internet]. 2011. Available from: http://www.ispor.org/OpenSourceIndex/ cached/cran.r-project.org/web/packages/mvna/..\%5Cnlme\%5Cindex.html

[30] Hothorn T, Bretz F, Westfall P. Simultaneous inference in general parametric models. Biometrical J 2008; 50(3): 346-63. 
578 [31] The R Development Core Team. R: A language and environment for statistical computing (ISBN 3-900051-07-0). Vienna, Austria: R Foundation for Statistical Computing; 2011. Available from: http://www.R-project.org/

[32] Garcia-Macias V, Martinez-Pastor F, Alvarez M, Garde JJ, Anel E, Anel L et al. Assessment of chromatin status (SCSA®) in epididymal and ejaculated sperm in Iberian red deer, ram and domestic dog. Theriogenology 2006;. 66(8): 192130.

[33] Martinez-Pastor F, Johannisson A, Gil J, Kaabi M, Anel L, Paz et al. Use of chromatin stability assay, mitochondrial stain jc-1, and fluorometric assessment of plasma membrane to evaluate frozen-thawed ram semen. Anim Reprod Sci 2004; 84(1-2): 121-33.

[34] Kastelic J, Cook R, Coulter G. Effects of ambient temperature and scrotal fleece cover on scrotal and testicular temperatures in rams. Can J Vet Res 1999; 63: $157-60$.

[35] Maloney SK, Bonomelli JM, DeSouza J. Scrotal heating stimulates panting and reduces body temperature similarly in febrile and non-febrile rams (Ovis aries). Comp Biochem Physiol A Mol Integr Physiol 2003; 135(4): 565-73.

[36] Dutt RH, Sand RS, Singh B. Changes in testis blood flow, the spermatic artery and prostaglandin $\mathrm{F}_{2}$ alpha content in testis tissue of heat-stressed rams. Int $\mathbf{J}$ Biometeorol 1977; 21(1): 75-84.

[37] Ibrahim NM, Romano JE, Troedsson MHT, Crabo BG. Effect of scrotal insulation on clusterin-positive cells in ram semen and their relationship to semen quality. J Androl 2001; 22(5): 863-77. 
601 [38] Manfredi Romanini MG, Boggiogera M, Formenti D, Fraschini A, Garagna S,

602

603

604

605

606

607

608

609

610

611

612

613

614

615

616

617

618

619

620

621

622

623

624
Pellicciari $\mathrm{C}$ et al. Sperm-chromatin maturation in the mouse. A cytochemical approach. Histochemistry 1986; 84(4-6): 484-91.

[39] Ward WS, Coffey DS. DNA packaging and organization in mammalian spermatozoa: Comparison with somatic cells. Biol Reprod 1991; 44(4): 569-74.

[40] Aitken RJ, De Iuliis GN. On the possible origins of DNA damage in human spermatozoa. Mol Hum Reprod 2010; 16(1): 3-13.

[41] Kasimanickam R, Pelzer KD, Kasimanickam V, Swecker WS, Thatcher CD. Association of classical semen parameters, sperm DNA fragmentation index, lipid peroxidation and antioxidant enzymatic activity of semen in ram-lambs. Theriogenology 2006; 65(7): 1407-21.

[42] Peris SI, Bilodeau JF, Dufour M, Bailey JL. Impact of cryopreservation and reactive oxygen species on DNA integrity, lipid peroxidation, and functional parameters in ram sperm. Mol Reprod Dev 2007; 74(7): 878-92.

[43] Rodriguez H, Ohanian C, Bustos-Obregon E. Nuclear chromatin decondensation of spermatozoa in vitro: A method for evaluating the fertilizing ability of ovine semen. Int J Androl 1985; 8(2): 147-58.

[44] Ibrahim SA. Seasonal variations in semen quality of local and crossbred rams raised in the United Arab Emirates. Anim Reprod Sci 1997; 49(2-3): 161-7.

[45] Avdi M, Banos G, Stefos K, Chemineau P. Seasonal variation in testicular volume and sexual behavior of Chios and Serres rams. Theriogenology 2004; 62(1-2): 275-82.

[46] Rekkas C, Kokolis N, Smokovitis A. Breed and seasonal variation of plasminogen activator activity and plasminogen activator inhibition in 

spermatozoa and seminal plasma of the ram in correlation with testosterone in the blood. Andrologia 1993; 25(2): 101-9.

[47] Afolayan RA, Fogarty NM, Gilmour AR, Ingham VM, Gaunt GM, Cummins LJ. Reproductive performance and genetic parameters in first cross ewes from different maternal genotypes. J Anim Sci 2008; 86(4): 804-14.

[48] Moule GR, Waites GMH. Seminal degeneration in the ram and its relation to the temperature of the scrotum. J Reprod Fertil 1963; 5(3): 433-46.

\section{Figure captions}

Figure 1. Daily mean values of microclimatic factors (ambient air temperature, ${ }^{\circ} \mathrm{C}$, and relative humidity, \%) and daily values of THI throughout a 12-month experimental period. Microclimatic factors were recorded in hourly intervals; daily maximum temperature and mean relative humidity were used for the calculation of the daily values of THI for one year, according to the formula proposed by Finocchiaro et al. [17].

Figure 2. Boxplots of daily values of SST $\left({ }^{\circ} \mathrm{C}\right)$ of nine rams measured over a 12month period, in relation to the month of SST measurement and the breed of ram. Boxes span the interquartile range (IQR; $25^{\text {th }}$ and $75^{\text {th }}$ percentiles are represented by the lower and upper hinges of boxes, respectively), with median values marked as horizontal lines within boxes. The lower and upper ends of whiskers represent the lower and higher values still within $1.5 \mathrm{IQR}$ of the $25^{\text {th }}$ and $75^{\text {th }}$ percentile, respectively; circular markers (Ë) represent values outside the 1.5 IQR. 
650 Figure 3. Boxplots of SCSA parameters (DFI, \%DFI), in relation to the month of 651 semen collection and the breed of ram. SCSA parameters were determined in frozen652 thawed semen samples, collected weekly from nine rams for a 12-month period. 653 Boxes span the interquartile range (IQR; $25^{\text {th }}$ and $75^{\text {th }}$ percentiles are represented by 654 the lower and upper hinges of boxes, respectively), with median values marked as 655 horizontal lines within boxes. The lower and upper ends of whiskers represent the 656 lower and higher values still within $1.5 \mathrm{IQR}$ of the $25^{\text {th }}$ and $75^{\text {th }}$ percentile, 657 respectively; circular markers $(\ddot{\mathrm{E}})$ and asterisks $(*)$ represent values outside the 1.5 658 IQR and extreme outliers, respectively. 


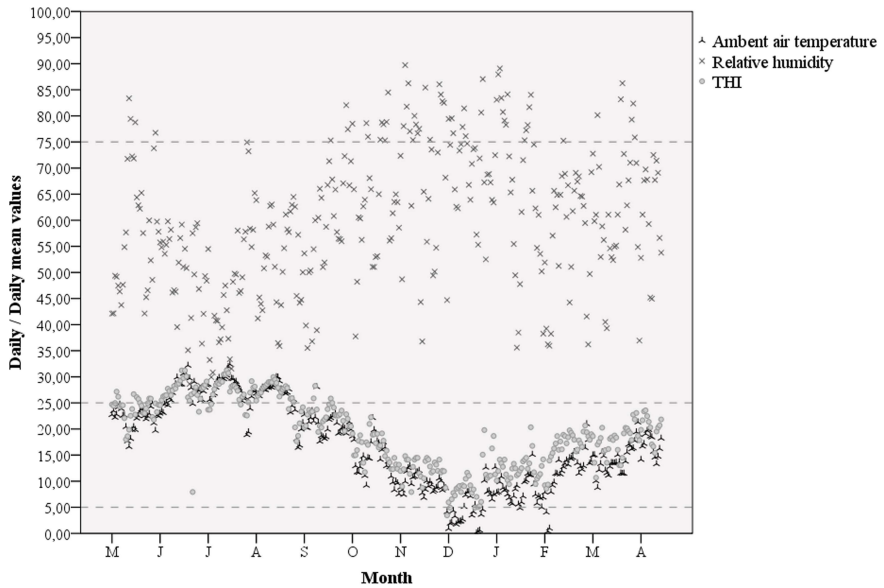




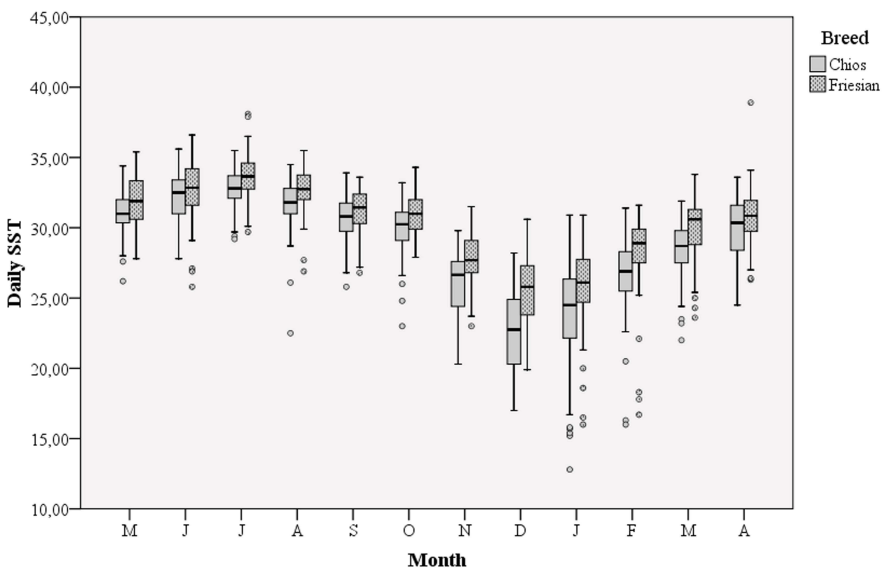


Table 1. Descriptive statistics of conventional and flow cytometrically assessed semen traits, daily scrotal surface temperature (SST), microclimatic factors (ambient air temperature, relative humidity) and daily temperature-humidity index (THI) over a 12-month experimental period. Semen traits were determined in frozen-thawed semen samples of nine rams ejaculating weekly for 12 months. Microclimatic factors were hourly recorded throughout the collection period.

\begin{tabular}{|c|c|c|c|c|}
\hline Variable & $\mathrm{N}$ & Mean \pm SD & Min & Max \\
\hline Ejaculate volume (mL) & 387 & $1.16 \pm 0.42$ & 0.2 & 2.8 \\
\hline $\begin{array}{l}\text { Sperm concentration } \\
\left(10^{6} \text { spermatozoa/mL }\right)\end{array}$ & 387 & $3975.50 \pm 1180.26$ & 1177.00 & 6414.00 \\
\hline $\begin{array}{l}\text { Total sperm count } \\
\left(10^{6} \text { spermatozoa }\right)\end{array}$ & 387 & $4719.23 \pm 2245.91$ & 235.4 & 17346.00 \\
\hline Motility (\%) & 387 & $67.36 \pm 13.97$ & 0.00 & 85.00 \\
\hline Viability (\%) & 387 & $73.77 \pm 11.56$ & 21.94 & 93.60 \\
\hline Normal spz (\%) & 387 & $78.48 \pm 12.77$ & 13.58 & 95.25 \\
\hline DFI & 387 & $175.62 \pm 2.93$ & 167.50 & 197.50 \\
\hline$\%$ DFI $(\%)$ & 387 & $6.58 \pm 3.79$ & 2.18 & 36.64 \\
\hline$\% \mathrm{VAI}(\%)$ & 387 & $10.50 \pm 8.21$ & 0.89 & 72.84 \\
\hline Temperature $\left({ }^{\circ} \mathrm{C}\right)$ & 8751 & $16.53 \pm 8.12$ & -4.33 & 40.13 \\
\hline Relative humidity (\%) & 8751 & $59.85 \pm 16.74$ & 23.40 & 94.60 \\
\hline THI & 365 & $19.05 \pm 6.22$ & 3.43 & 31.26 \\
\hline $\operatorname{SST}\left({ }^{\circ} \mathrm{C}\right)$ & 2812 & $29.43 \pm 3.56$ & 12.80 & 38.90 \\
\hline
\end{tabular}

N: sample size, SD: standard deviation 
Table 2. Fixed effects included (+) in the built-up of the MLMs that were found most adequate (among eight time periods) to describe the relation of SCSA parameters to the independent variables; fixed effects not improving the goodness-of-fit of the MLMs were excluded (-). The time period presenting the most adequate MLM for each SCSA parameter was determined by comparing the goodness-of-fit of different MLMs within and between time periods with ANOVA $(\mathrm{P}<0.05)$.

\begin{tabular}{ccccccc}
\hline \multirow{2}{*}{$\begin{array}{c}\text { Dependent } \\
\text { variable }\end{array}$} & \multicolumn{5}{c}{ Fixed effects } & Time $^{\text {Time }}$ \\
\cline { 2 - 5 } & Breed & Age & Month & SST $_{\text {mean }}$ & THI $_{\text {mean }}$ & period $^{\mathrm{a}}$ \\
DFI & + & + & + & + & - & 7 \\
\%FI & + & + & + & + & - & 1 \\
\hline
\end{tabular}

${ }^{\mathrm{a}}$ presenting the best-fitting MLM for each dependent variable. 
Table 3. Estimated regression coefficients (b) and P-values of fixed effects included in the best-fitting MLMs, as presented in Table 2.

\begin{tabular}{ccccc}
\hline $\begin{array}{c}\text { Dependent } \\
\text { variable }\end{array}$ & Time period & Fixed effect & $\mathrm{b} \pm \mathrm{SEM}$ & P-value \\
\hline DFI & 7 & Breed 1 & $0.00^{\mathrm{a}}$ & \\
& Breed 2 & $1.041 \pm 0.218$ & $<0.001$ \\
& Age class 1 & $0.00^{\mathrm{b}}$ & \\
& Age class 2 & $0.149 \pm 0.227$ & 0.512 \\
& Age class 3 & $0.141 \pm 0.338$ & 0.676 \\
& Month & $0.279 \pm 0.112$ & 0.017 \\
& SST mean & $-0.263 \pm 0.068$ & $<0.001$ \\
& Breed 1 & $0.00^{\mathrm{a}}$ & \\
& Breed 2 & $0.690 \pm 0.294$ & 0.019 \\
& Age class 1 & $0.00^{\mathrm{b}}$ & \\
& Age class 2 & $-0.603 \pm 0.319$ & 0.059 \\
& Age class 3 & $-1.187 \pm 0.476$ & 0.013 \\
& Month & $0.162 \pm 0.060$ & 0.010 \\
& SST & $-0.179 \pm 0.061$ & 0.004 \\
\hline
\end{tabular}

b: mean estimated regression coefficient, SEM: standard error of mean, breeds 1 and

2: Chios and East Friesian, respectively, age classes 1 to 3: 2, 3 to 4 and 6 years old, respectively.

${ }^{\text {a }}$ Breed 1 is set as a baseline for the categorical variable breed; the estimated regression coefficient $b$ represents the difference (in units of the outcome) between the two breeds, when all other dependent variables are constant.

${ }^{b}$ Age class 1 is set as a baseline for the categorical variable age; the estimated regression coefficient $b$ represents the difference (in units of the outcome) between different age classes, when all other dependent variables are constant. 